\title{
Kinetics of CO Oxidation Catalyzed by Supported Gold: A Tabular Summary of the Literature
}

\author{
Veronica Aguilar-Guerrero • Bruce C. Gates
}

Received: 15 December 2008/ Accepted: 17 February 2009/Published online: 4 March 2009

(c) The Author(s) 2009. This article is published with open access at Springerlink.com

\begin{abstract}
The literature of $\mathrm{CO}$ oxidation catalyzed by supported gold is extensive, but reports of the kinetics of the reaction are incomplete and fragmented. This paper is a summary of such information presented in tables that state (1) how the catalysts were made, treated, and tested; (2) their physical properties, such as the average gold particle size; and (3) kinetics data, including turnover frequencies, reaction orders, and apparent activation energies.
\end{abstract}

Keywords Gold catalyst - Supported gold .

$\mathrm{CO}$ oxidation $\cdot$ Kinetics of $\mathrm{CO}$ oxidation

\section{Introduction}

Extensive research on catalysis by supported gold has been reported since the pioneering discoveries by Hutchings [1] and Haruta [2] demonstrating high catalytic activities of highly dispersed gold. $\mathrm{CO}$ oxidation and the water gas shift are among the best investigated of the reactions catalyzed by supported gold; most of the work has focused on the former [3], as it apparently offers the advantages of taking place at low temperatures combined with the simplicity of small reactant molecules and the value of $\mathrm{CO}$ as a sensitive probe of surface structure [4].

Notwithstanding the extensive research on supported gold catalysts for $\mathrm{CO}$ oxidation, the mechanism(s) of the reaction and the catalytically active species remain matters of debate, and the reports of quantitative kinetics of the reaction, although numerous, are largely incomplete.

V. Aguilar-Guerrero · B. C. Gates ( $\square)$

Department of Chemical Engineering and Materials Science,

University of California, Davis, CA 95616, USA

e-mail: bcgates@ucdavis.edu
The lack of thorough kinetics data reflects the complexities of the catalyst performance, influenced by catalyst activation and deactivation, which are often rapid; it is sometimes difficult to determine from published reports whether the reaction rates or conversions characterize fresh or deactivated catalysts.

Our goal was to provide a summary facilitating access to the literature of the kinetics of $\mathrm{CO}$ oxidation catalyzed by supported gold. The literature is summarized here in tabular form; earlier, much less complete summaries were reported by Bond et al. [5], Deng et al. [6], and Kung et al. [7]. Some issues regarding the challenges of comparing supported gold catalysts on the basis of performance were addressed by Long et al. [8]. We have limited the content here by excluding catalysts with doped supports (except when they were part of a set including undoped supports) and results characterizing "preferential oxidation" of $\mathrm{CO}$ in the presence of excess $\mathrm{H}_{2}$. Otherwise, the compilation contains most of the literature that includes kinetics data for $\mathrm{CO}$ oxidation catalyzed by supported gold, although it is not exhaustive, with a number of examples of only partially documented kinetics data being omitted.

\section{Tables of Data}

The data are presented in three tables, with the entries linked by the entry number shown in the left-hand column of each table. Table 1 is a list of supported gold catalysts used for $\mathrm{CO}$ oxidation, how they were made and treated, their gold contents and surface areas, and the average gold particle sizes and methods used to determine them. Table 2 is a summary of the conditions under which the kinetics data were determined, with information about the degree of deactivation of the catalyst. Table 3 is a summary of the kinetics data, 


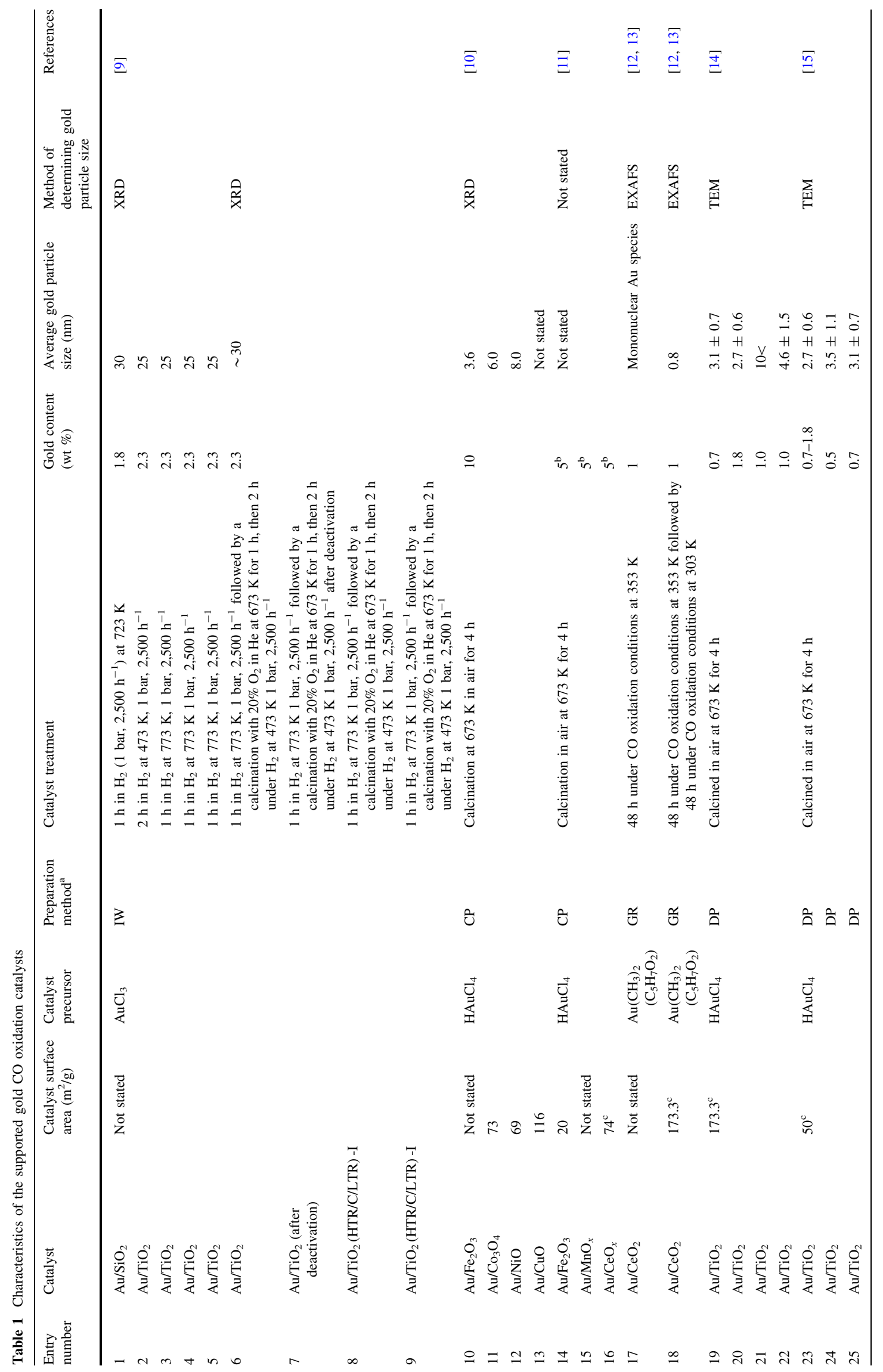




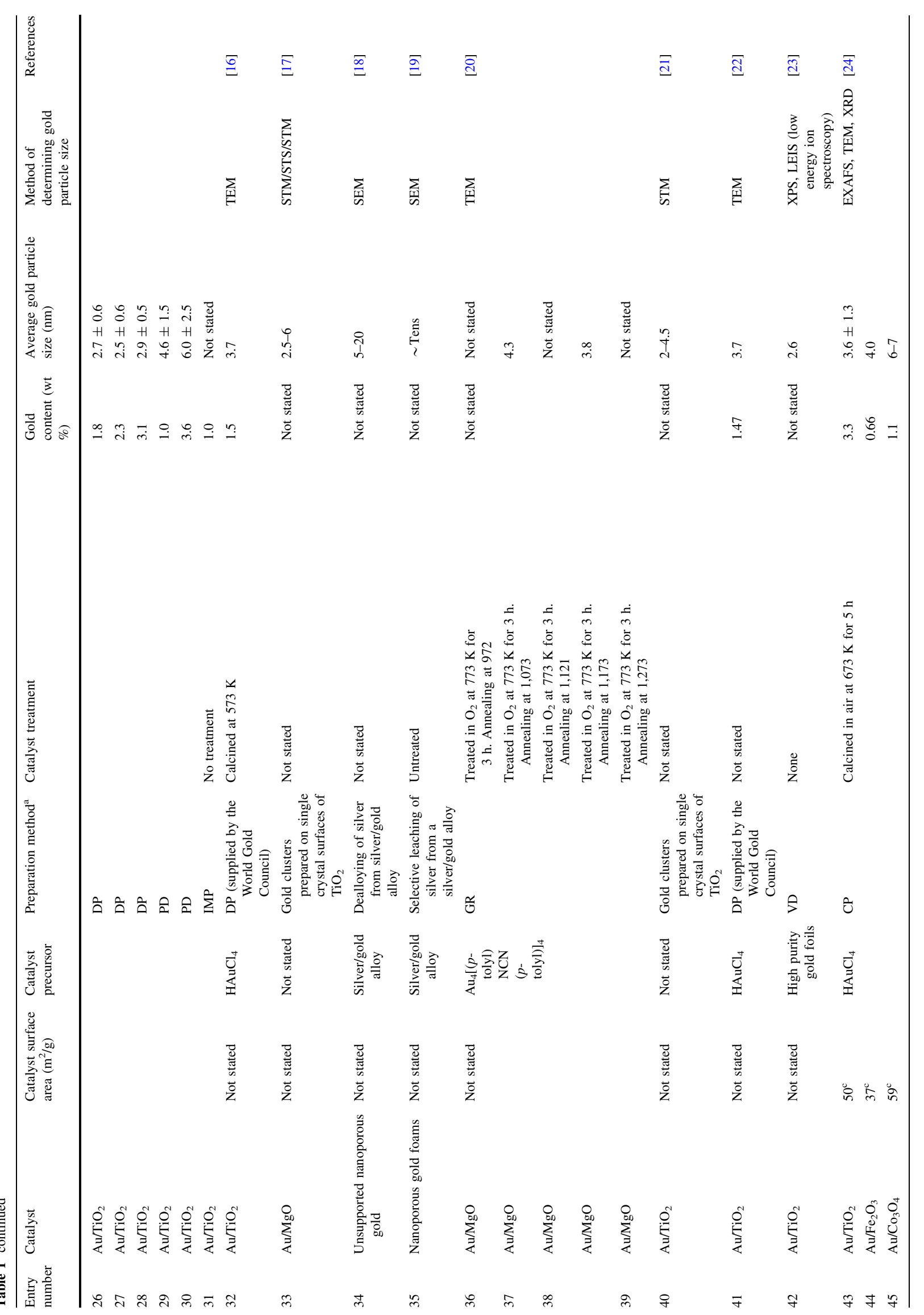




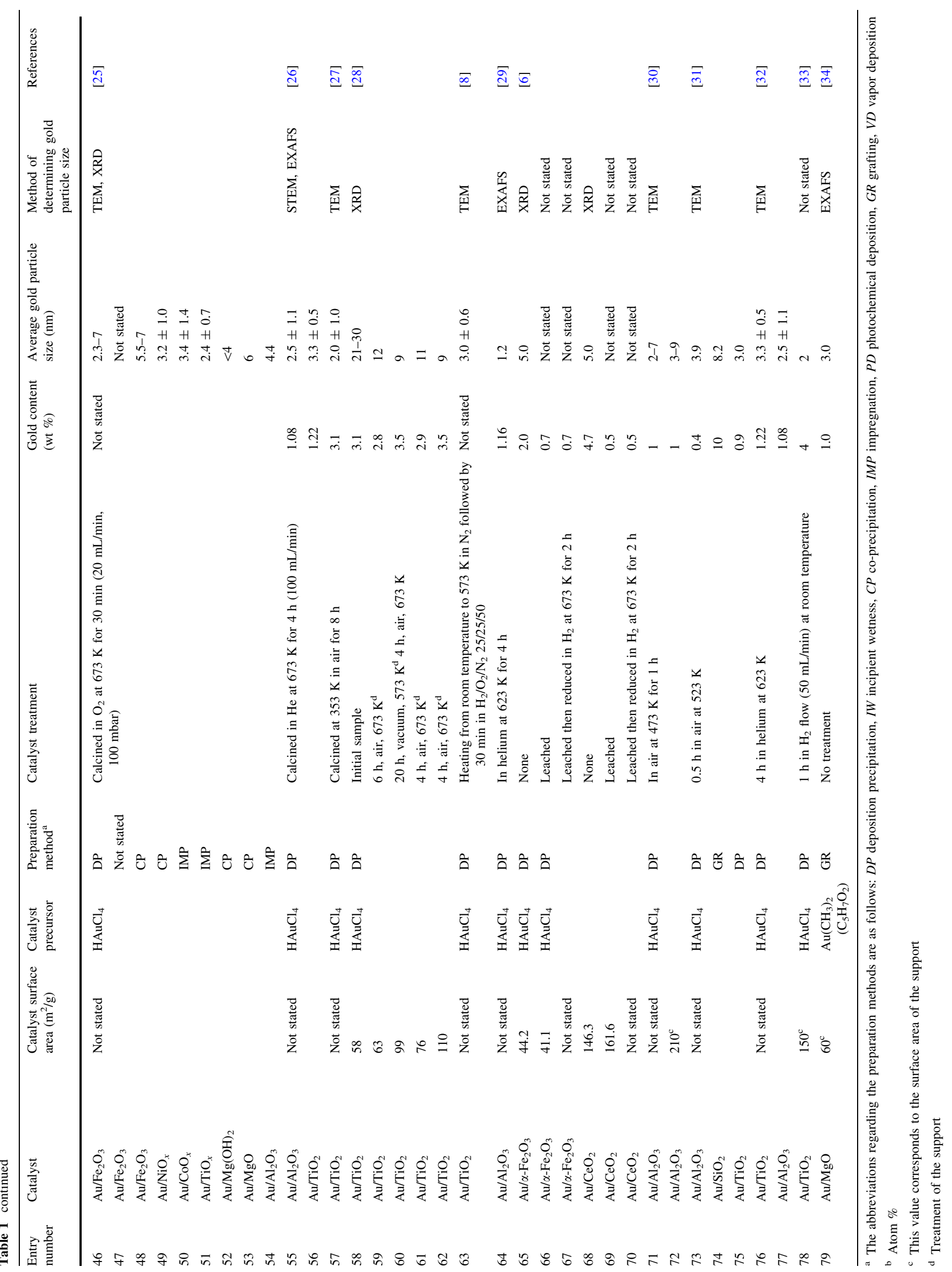




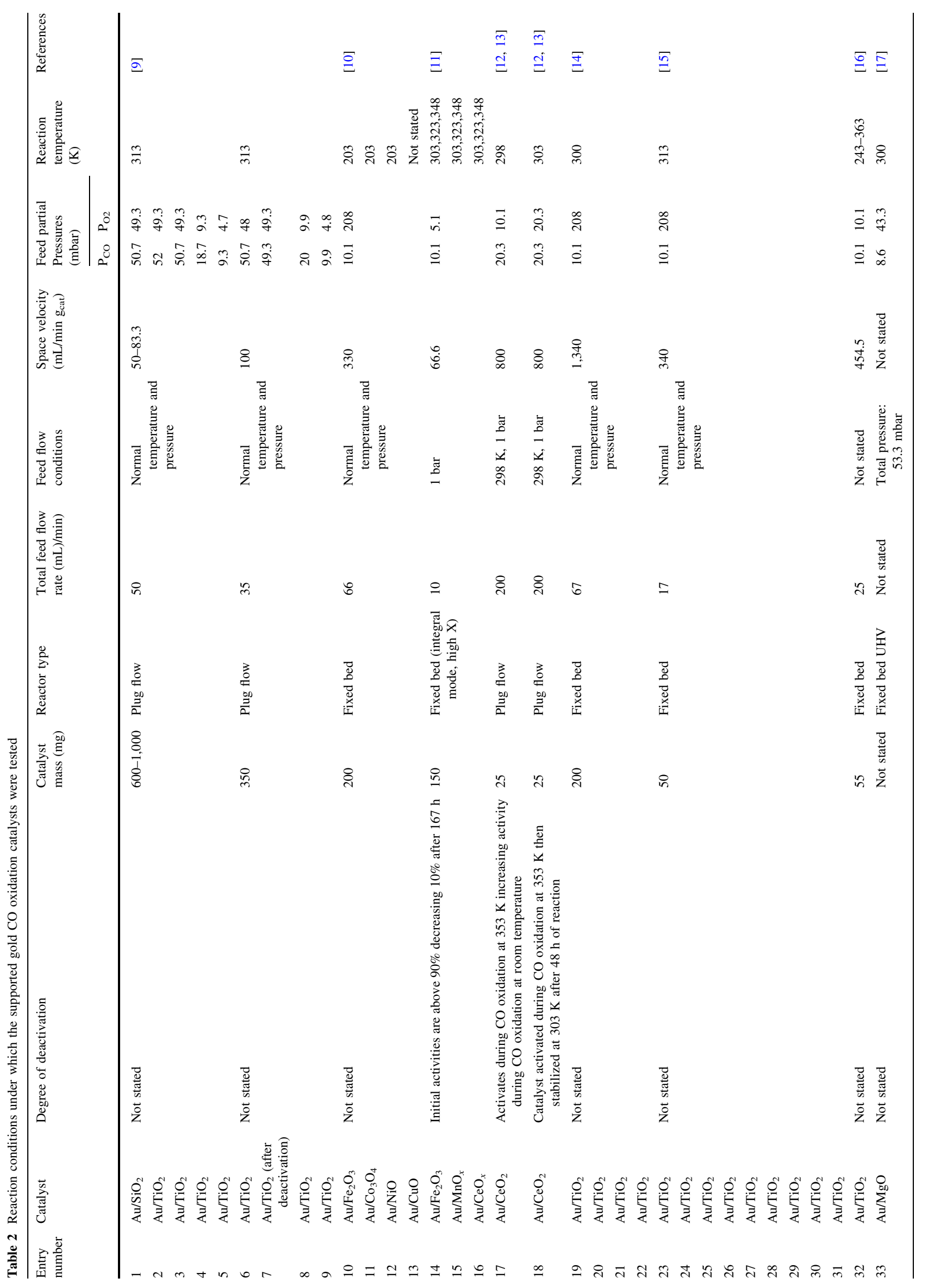




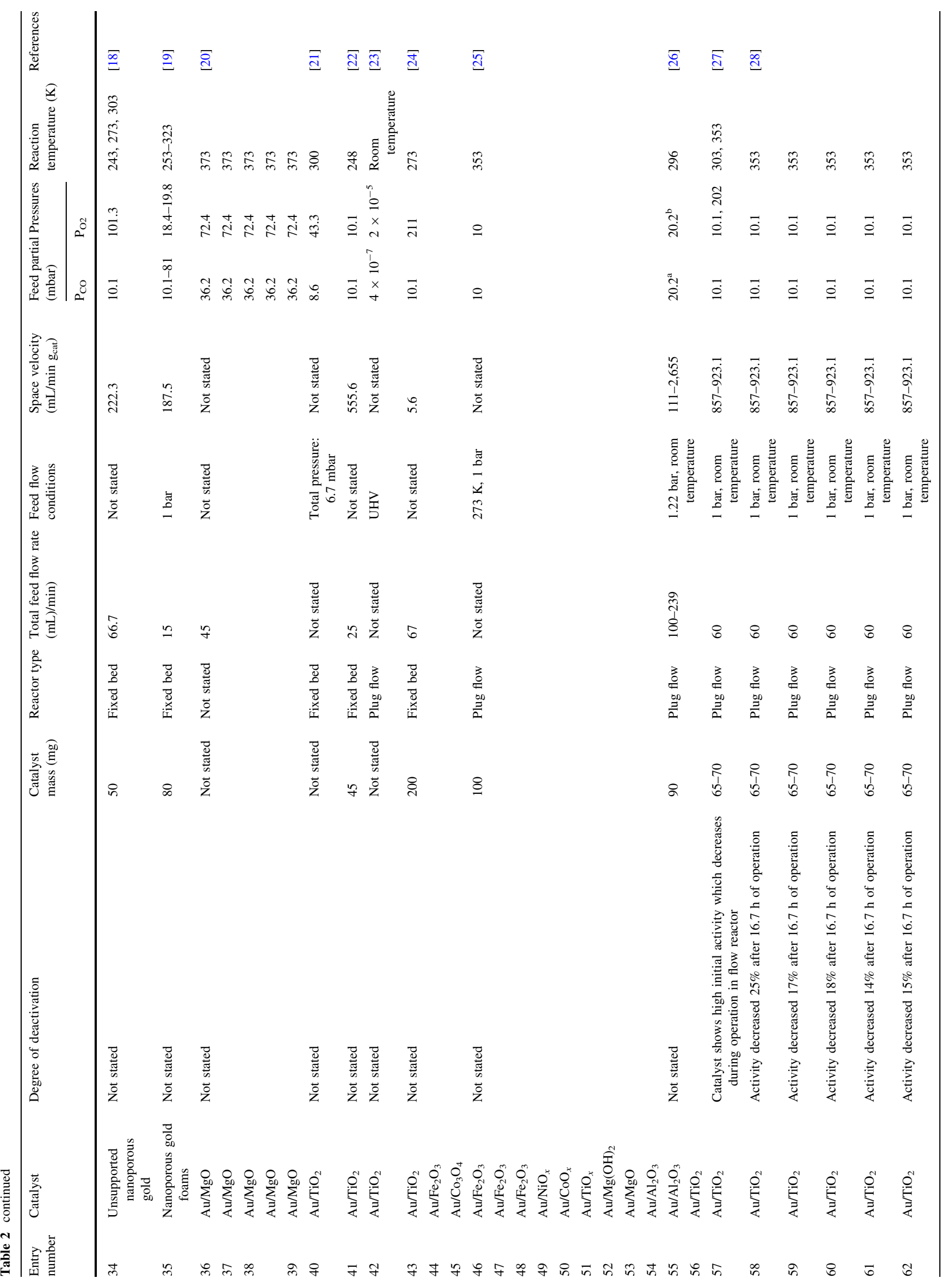




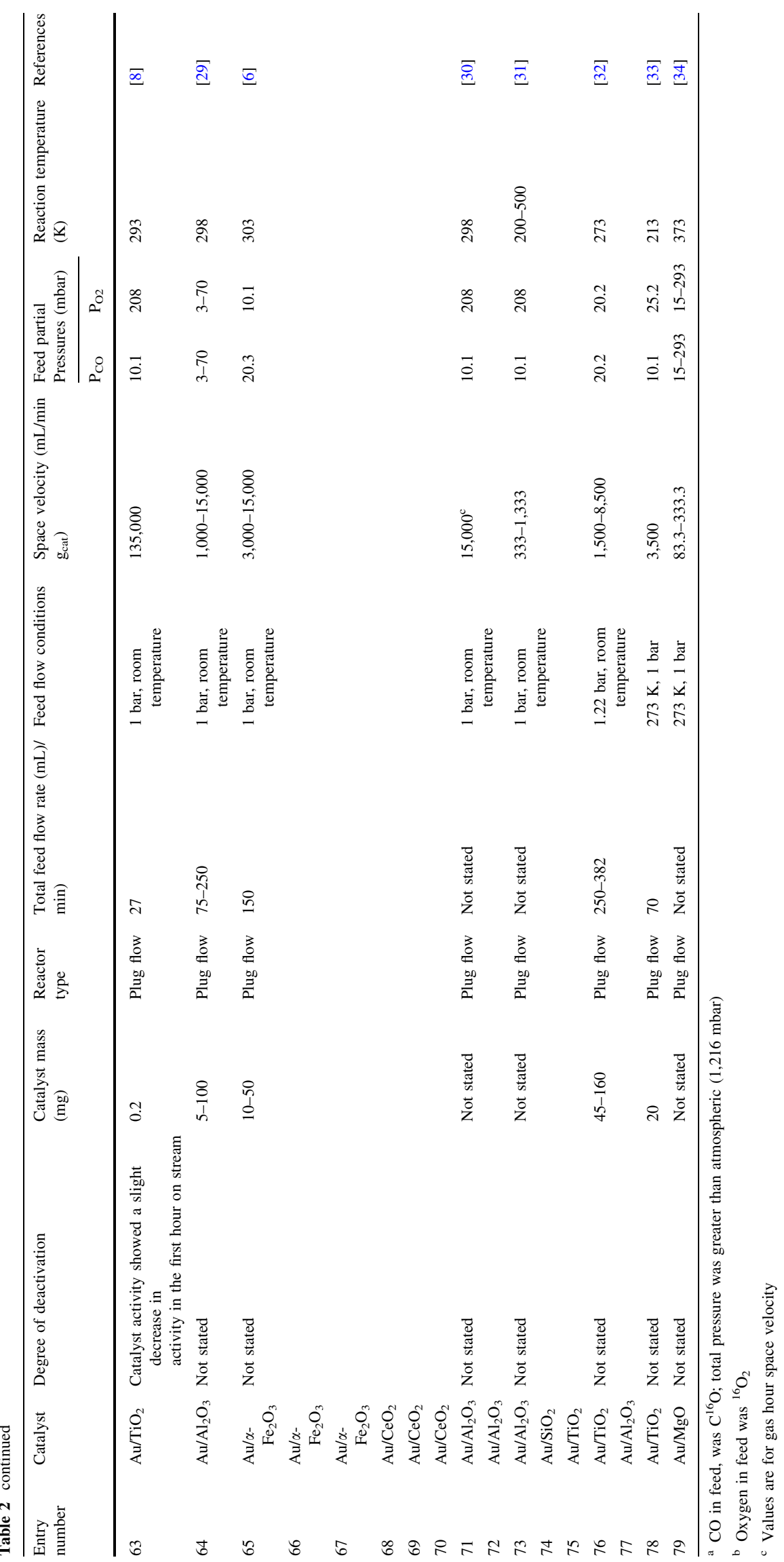




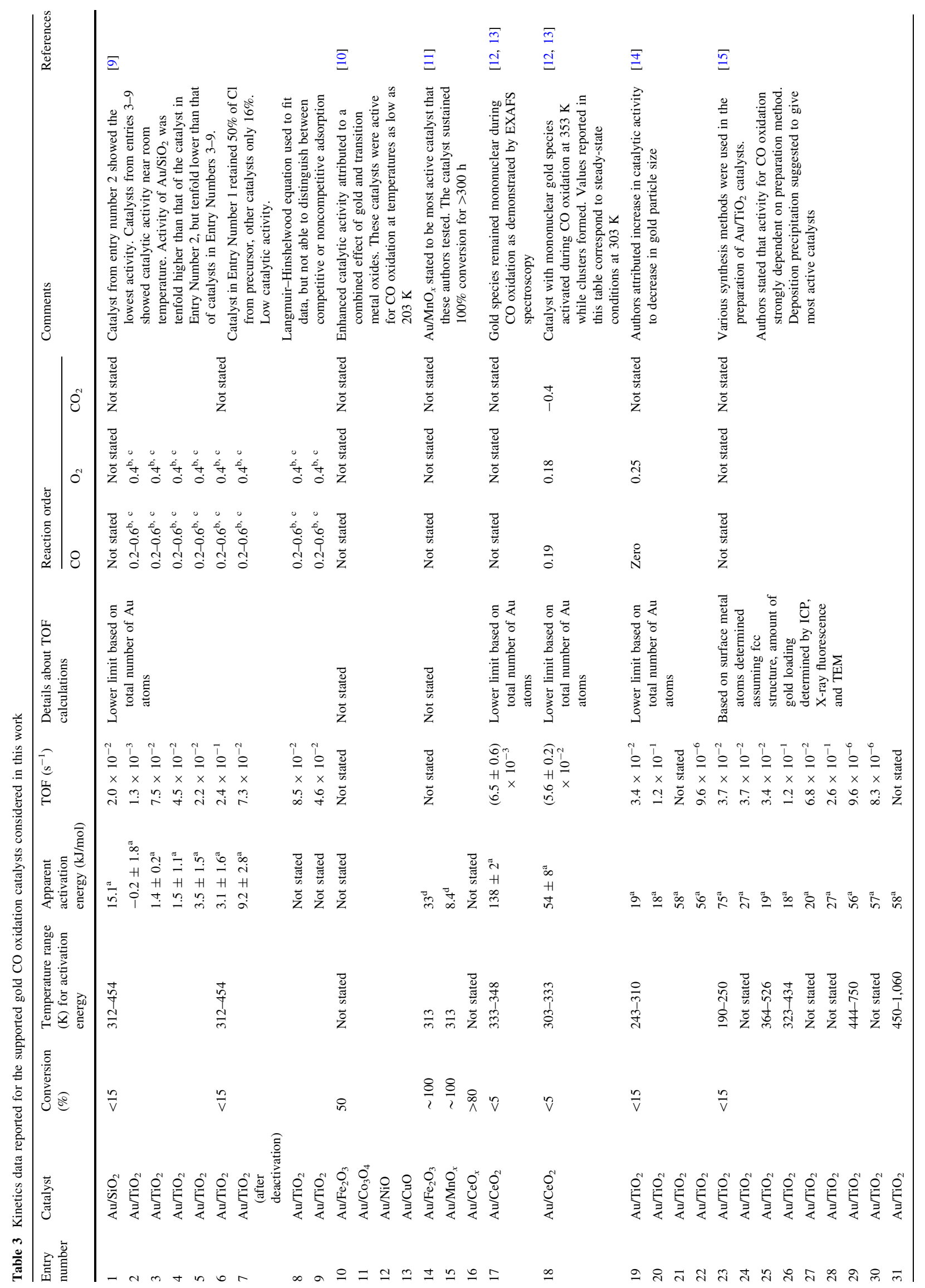




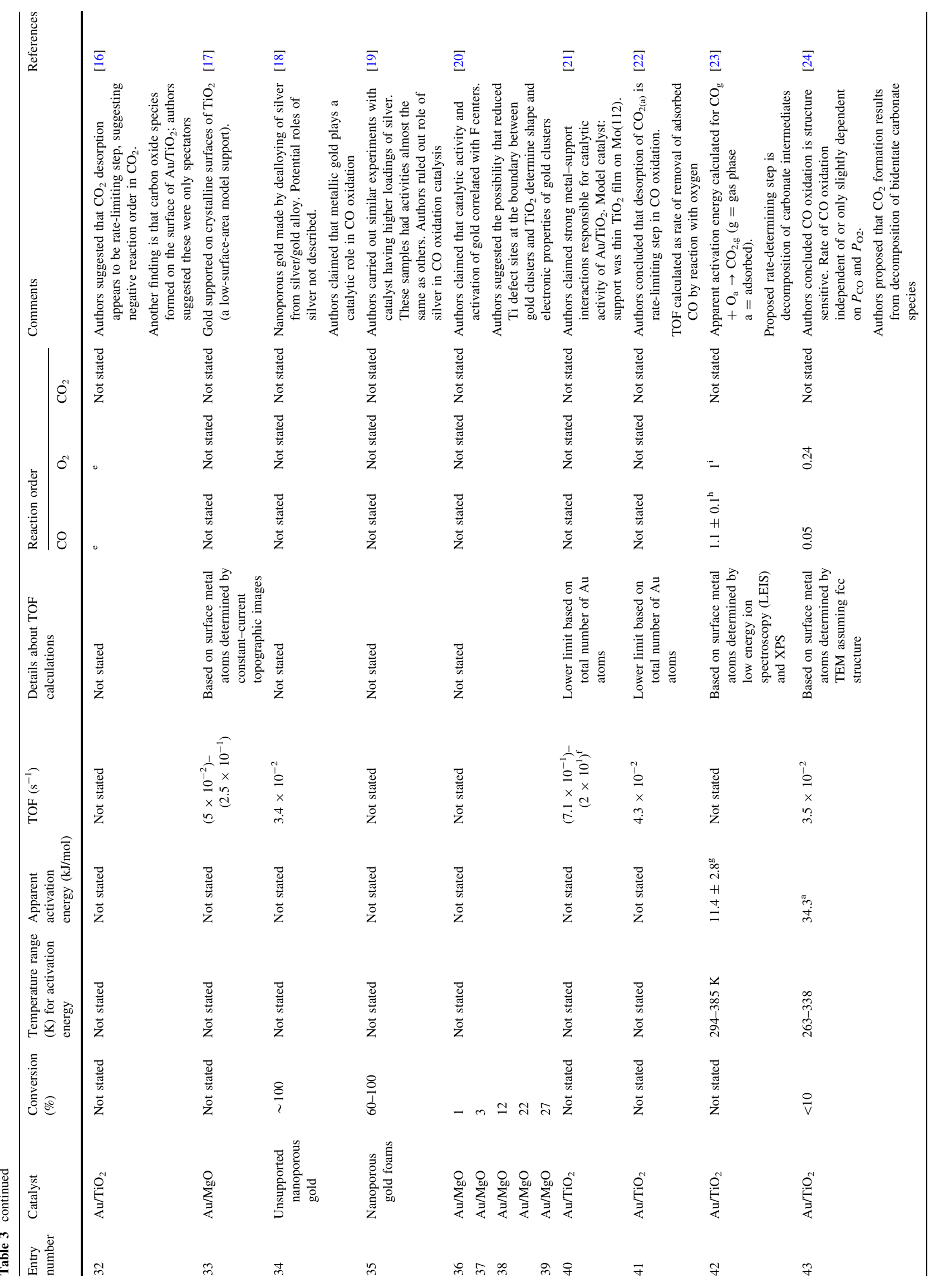




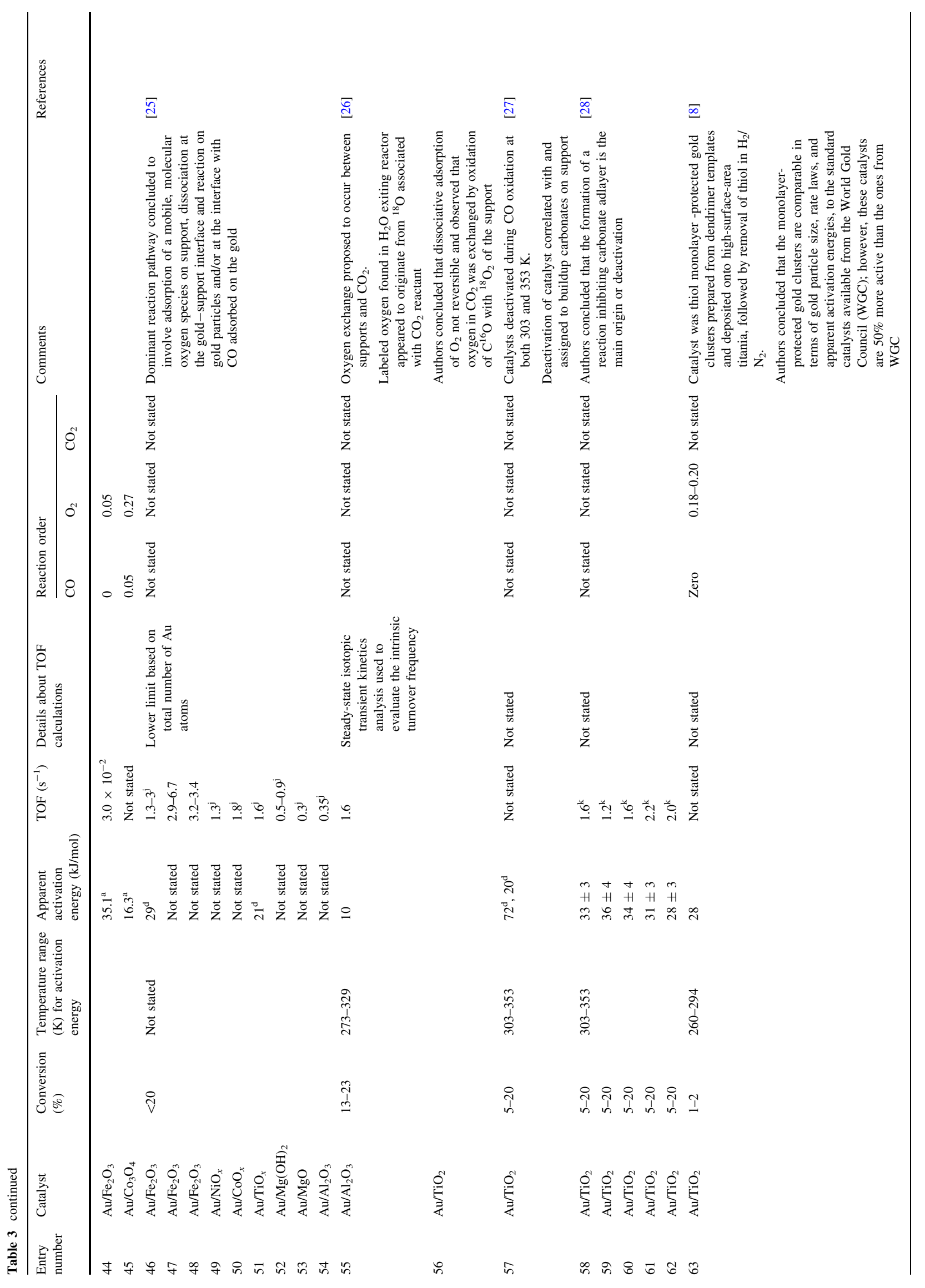




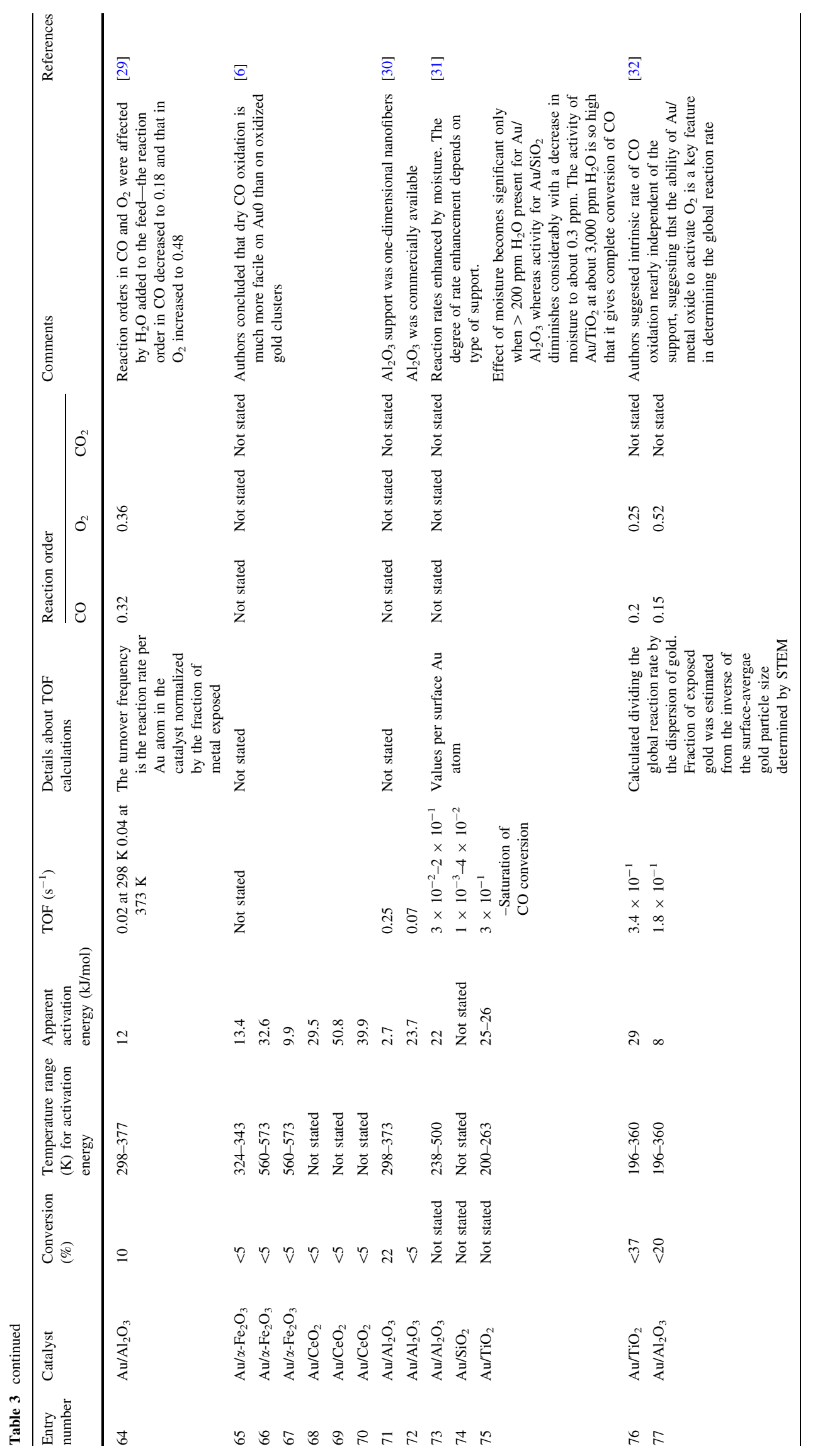




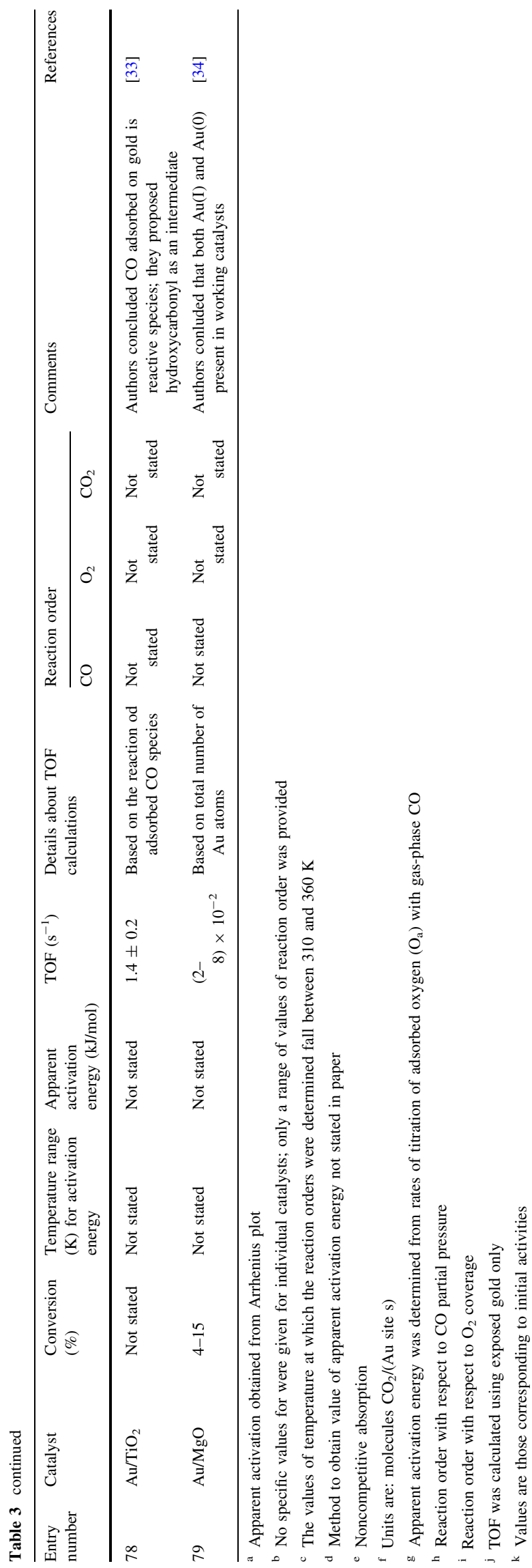

including values of TOF and how they were determined, reaction orders, and apparent activation energies.

We believe that these tables provide the most complete available statement of kinetics of $\mathrm{CO}$ oxidation catalyzed by supported gold.

\section{Generalizations Based on the Data}

Table 2 is a summary of the catalysts tested for CO oxidation; the catalysts were investigated at temperatures in the range of 203-373 K. Haruta [35] referred to a lowtemperature regime (typically, $\sim 210 \mathrm{~K}$ ) and a high-temperature regime (typically, $>300 \mathrm{~K}$ ). The $\mathrm{O}_{2}$ partial pressures were varied between 4 and $200 \mathrm{mbar}$, and the $\mathrm{CO}$ partial pressures between 10 and 40 mbar. The results indicate orders of reaction in $\mathrm{CO}$ and in $\mathrm{O}_{2}$ in the range 0.0-0.6. The reaction order in $\mathrm{CO}$ has been approximated as zero by some researchers [24]. Correspondingly, numerous researchers have postulated that $\mathrm{CO}$ is adsorbed on the gold; some [4] have suggested that $\mathrm{CO}$ is bonded to gold at the gold-support interface.

The roles of oxygen in the gold-catalyzed $\mathrm{CO}$ oxidation are evidently not fully elucidated. Some authors have postulated that oxygen adsorbed on the gold [4] or at the gold-support interface [36] may play a role. In contrast, Guzman et al. [37] reported evidence of the involvement of reactive oxygen species (such as superoxides) on their $\mathrm{CeO}_{2}$ support; the influence of the presence of reactive oxygen species on some supports but not on others (e.g., $\gamma$ $\mathrm{Al}_{2} \mathrm{O}_{3}$ [38]) would suggest that the form of kinetics would differ from one support to another, but there are too few data to test this statement.

A few reports of the influence of $\mathrm{CO}_{2}$ on the rate indicate that it inhibits the reaction; according to one report [16, 22], the desorption of $\mathrm{CO}_{2}$ from $\mathrm{Au} / \mathrm{TiO}_{2}$ is rate limiting under some conditions. Others [39] have reported that $\mathrm{CO}_{2}$ (rather than $\mathrm{O}_{2}$ ) is the oxidizing agent of gold in supported gold catalysts, implying that the gold in the catalytic sites cycles between more than one oxidation state.

Haruta's group [40] reported a detailed investigation of the influence of water in the reactant stream on $\mathrm{CO}$ oxidation catalyzed by $\mathrm{TiO}_{2}{ }^{-}, \mathrm{Al}_{2} \mathrm{O}_{3}{ }^{-}$, and $\mathrm{SiO}_{2}{ }^{-}$supported gold. Water in low concentrations increases the activity of the catalyst.

The most thorough investigation of the kinetics of $\mathrm{CO}$ oxidation catalyzed by supported gold was reported by Vannice's group [9]; the catalyst support was $\mathrm{TiO}_{2}$. The authors tested several catalysts that had been subjected to various pretreatments, and kinetics parameters are reported for each (entry numbers 1-9 in Tables 1, 2, 3).

Many of the most active supported gold catalysts for $\mathrm{CO}$ oxidation are supported on $\mathrm{TiO}_{2}$ or on various oxides of iron 
or of cerium. Turnover frequencies (rates of reaction per accessible gold site; Table 3) span a wide range, between $10^{-6}$ and $10^{-1} \mathrm{~s}^{-1}$. There is one report of an intrinsic turnover frequency - that is, per active site [41] (entry numbers $55,56,64,76$, and 77, Tables 1,2,3)-determined in transient measurements with isotopically labeled reactant ${ }^{13} \mathrm{CO}$ for $\mathrm{Au} / \gamma-\mathrm{Al}_{2} \mathrm{O}_{3}$; the value is $1.6 \times 10^{-1} \mathrm{~s}^{-1}$ at $296 \mathrm{~K}$ and $\mathrm{CO}$ and $\mathrm{O}_{2}$ partial pressures of 24.2 mbar each.

Only a few values of apparent activation energies of $\mathrm{CO}$ oxidation catalyzed by gold have been reported, and the information about the conditions under which they were determined is often lacking. The apparent activation energies range from values that are essentially indistinguishable from 0 to $138 \mathrm{~kJ} / \mathrm{mol}$ (Table 3).

Most reports of catalyst deactivation and how it occurs (e.g., [11]) do not include kinetics data, but the work of Vannice's group [9] is exceptional, providing kinetics data for various catalysts before and after deactivation (Table 2).

Supported gold catalysts typically undergo rapid deactivation during $\mathrm{CO}$ oxidation, and this complication has hindered the collection of kinetics data. For example, the initial conversion observed with a zeolite-supported gold catalysts was about $40 \%$, and this decreased to $<5 \%$ within $15 \mathrm{~min}$ of operation in a once-through flow reactor at $298 \mathrm{~K}$ [42]. An $\mathrm{Au} / \mathrm{TiO}_{2}$ [27] catalyst, on the other hand, showed an initial conversion at $303 \mathrm{~K}$ of nearly $100 \%$, and the conversion had declined to $10 \%$ after $2,000 \mathrm{~min}$ of operation in a flow reactor when $\mathrm{O}_{2}$ was present in stoichiometric excess; but the decline in activity was more rapid when the $\mathrm{O}_{2}$ was not present in stoichiometric excess. Other authors have also observed that the rate of catalyst deactivation was less when the reaction took place in an $\mathrm{O}_{2}$-rich atmosphere [25].

It is clear that the available data do not lend themselves to conclusive integration and that much work remains to be done to consolidate the literature and to represent $\mathrm{CO}$ oxidation catalyzed by supported gold quantitatively.

\section{Conclusions}

The results summarized here show that the literature of $\mathrm{CO}$ oxidation catalyzed by supported gold is extensive but fragmented and not easily generalized; it is not easy to make meaningful comparisons of various supported gold catalysts for this reaction, and much work remains to be done to consolidate the literature of $\mathrm{CO}$ oxidation catalyzed by supported gold.

Open Access This article is distributed under the terms of the Creative Commons Attribution Noncommercial License which permits any noncommercial use, distribution, and reproduction in any medium, provided the original author(s) and source are credited.

\section{References}

1. Hutchings GJ (2005) Catal Today 100:55

2. Haruta M, Kobayashi T, Sano H, Yamada N (1987) Chem Lett 405

3. Hashmi S, Hutchings GJ (2006) Angew Chem Int Ed 45:7896

4. Mihaylov M, Knözinger H, Hadjiivanov K, Gates BC (2007) Chem Ing Tech 79:795

5. Bond GC, Louis C, Thompson DT (2006) Catalytic series V.6: catalysis by gold. World Scientific Imperial College Press, London

6. Deng W, Carpenter C, Yi N, Flytzani-Stephanopoulos M (2007) Topics Catal 44:199

7. Kung MC, Davis RJ, Kung HH (2007) J Phys Chem C 111:11767

8. Long CG, Gilbertson JD, Vijayarahavan G, Stevenson KJ, Pursell CJ, Chandler BD (2008) J Am Chem Soc 130:10103

9. Lin SD, Bollinger M, Vannice MA (1993) Catal Lett 17:245

10. Haruta M, Yamada N, Kobatashi T, Ijima S (1989) J Catal 301

11. Gardner S, Hoflund GB (1991) Langmuir 7:2135

12. Aguilar-Guerrero V, Gates BC (2007) Chem Comm 3210

13. Aguilar-Guerrero V, Gates BC (2008) J Catal 260:351

14. Haruta M (2004) J New Mat Electrochem Systems 7:163

15. Bamwenda GR, Tsubota S, Nakamura T, Haruta M (1997) Catal Lett $44: 83$

16. Chang B, Jang BW, Dai S, Overbury SH (2005) J Catal 236:392

17. Valden M, Lai X, Goodman DW (1998) Science 281:1647

18. Xu C, Su J, Xu X, Liu P, Zhao H, Tian F, Ding Y (2007) J Am Chem Soc 129:42

19. Zielasek V, Jürgens B, Schulz C, Biener J, Biener MM, Hamza AV, Bäumer M (2006) Angew Chem Int Ed 45:8241

20. Yan Z, Chinta S, Mohamed AA, Fackler JP, Goodman DW (2005) J Am Chem Soc 127:1604

21. Goodman DW (2005) Catal Lett 99:1

22. Clark JC, Dai S, Overbury SH (2007) Catal Today 126:135

23. Bondzie VA, Parker SC, Campbell CT (1999) Catal Lett 63:143

24. Haruta M, Tsubota S, Kobayashi T, Kageyama H, Genet MJ, Delmon B (1993) J Catal 144:175

25. Schubert MM, Hackenberg S, van Veen AC, Muhler M, Plzak V, Behm RJ (2001) J Catal 197:113

26. Calla JT, Davis RJ (2006) J Catal 241:407

27. Denkwitz Y, Zhao Z, Hörmann U, Kaiser U, Plzak V, Behm RJ (2007) J Catal 251:363

28. Denwitz Y, Geserik J, Hörmann U, Plzak V, Kaiser U, Hüsing N, Behm RJ (2007) Catal Lett 119:199

29. Calla JT, Davis RJ (2005) Ind Eng Chem Res 44:5403

30. Han Y, Zhong Z, Ramesh K, Chen F, Chen L (2007) J Phys Chem C 111:3163

31. Date M, Okumura M, Tsubota M, Haruta M (2004) Angew Chem Int Ed 43:2129

32. Calla JT, Bore MT, Datye AK, Davis RJ (2006) J Catal 238:458

33. Henao JD, Caputo T, Yang JH, Kung MC, Kung HH (2006) 110:8689

34. Guzman J, Gates BC (2004) 129:26

35. Haruta M (2008) In: Corain B, Schmid G, Toshima N (eds) Relevance of metal nanoclusters in catalysis and materials science: the issue of size control, ch 9. Elsevier, Amsterdam, p 183

36. Bond GC, Thompson DT (1999) Catal Rev Sci Eng 41:319

37. Guzman J, Carrettin S, Fierro-Gonzalez JC, Hao Y, Gates BC, Corma A (2005) Angew Chem Int Ed 117:4856

38. van Bokhoven JA, Louis C, Miller JT, Tromp M, Safonova OV, Glatzel P (2006) Angew Chem Int Ed 45:465

39. Mihaylov M, Ivanova E, Hao Y, Hadjiivanov K, Gates BC, Knözinger H (2008) Chem Comm 175

40. Daté M, Okumura M, Tsubota S, Haruta M (2004) Angew Chem Int Ed 43:21

41. Calla JT, Davis RJ (2005) J Phys Chem B 109:2307

42. Fierro-Gonzalez JC, Gates BC (2004) J Phys Chem B 108:16999 